\title{
Is Rhodamine a good tracer to predict coal transport in water?
}

\author{
¿Es la rodamina un buen trazador para predecir el transporte de carbón en agua?
}

\section{Patricio Winckler ${ }^{1,2,3}$, Francisco Molteni ${ }^{1}$, Mauricio Reyes ${ }^{1}$, Alejandra Gubler $^{3}$, Jorge Sandoval ${ }^{4}$ and Rui Aleixo ${ }^{5}$}

${ }^{1}$ Escuela de Ingeniería Civil Oceánica, Universidad de Valparaíso, Valparaíso, Chile, patricio.winckler@uv.cl, fco.molteni@gmail.com, mauricio.reyes@uv.cl

${ }^{2}$ Centro de Observación Marino para estudios de Riesgos del Ambiente Costero COSTAR-UV, Valparaíso, Chile

${ }^{3}$ Centro de Investigación y Gestión de Desastres Naturales CIGIDEN, Macul, Chile, alejandra.gubler@alumnos.usm.cl

${ }^{4}$ Departamento de Ingeniería Hidráulica y Ambiental, Pontificia Universidad Católica de Chile, Macul, Chile, jcsandov@uc.cl

${ }^{5}$ CERIS Civil Engineering Research for Innovation and Sustainability, University of Lisbon, Portugal, rui.aleixo@tecnico.ulisboa.pt

A simple and low-cost experimental procedure to compare the mixing and transport of two substances in water is presented in this paper, aiming to investigate if rhodamine can predict the fate of coal transport in water. The procedure is based on acoustic Doppler techniques to characterize the flow and imaging techniques to measure the transport of substances discharged from an instantaneous point source near the free surface. To validate this procedure, several tests are carried out for rhodamine and two subsamples of coal (defined by a fine and coarse granulometry) in a flume under currents. The results show that the mixing of rhodamine resembles the finest fraction of coal that is transported as a suspended material, but fails to characterize the larger coal grains that experience sedimentation. The procedure here proposed can be expanded to characterize the mixing of substances in a body of water under other conditions, such as waves or wind driven currents.

Keywords: coal, rhodamine, advection, turbulent diffusion, image processing
En este artículo se presenta un procedimiento experimental simple y de bajo costo para comparar la mezcla y el transporte de sustancias en el agua, con el objetivo de investigar si la rodamina puede predecir el destino del transporte de carbón en el agua. El procedimiento se basa en técnicas Doppler acústico para caracterizar el flujo y técnicas de procesamiento de imágenes para medir el transporte de sustancias descargadas desde una fuente puntual instantánea cerca de la superficie libre. Para validar el procedimiento, se realizan ensayos de rodamina y muestras de carbón (de granulometría fina y gruesa) en un canal de corrientes. Los resultados muestran que la mezcla de rodamina se asemeja a la fracción más fina de carbón transportado como material en suspensión, pero no caracteriza los granos de carbón más grandes que sedimentan. El procedimiento propuesto puede ampliarse para caracterizar la mezcla de sustancias en otras condiciones, como olas o corrientes.

Palabras clave: carbón, rodamina, advección, difusión turbulenta, procesamiento de imágenes

\section{Introduction}

Coal is an organic rock originated by a geological process known as coalification. Coal can show a variety of properties, mainly dependent on the original vegetal and mineral matter, biological and chemical processes, the conditions of pressure and temperature, and the time span

while coalification occurs (Schweinfurth, 2009). This raw material played a major role in the industrial revolution as fuel for steam engines (Schweinfurth, 2009). Throughout the 20th century, coal has been one of the main energy sources, accounting today to $38 \%$ of the world's electricity generation (WCA, 2020). Coal combustion contributes 
to the emission of greenhouse gases, liquid effluents and solid wastes (IEA, 2011), with global consequences such as the increase in global temperature and local effects in heavily industrialized areas. Furthermore, coal contains trace metals/metalloids and potential toxicants which are harmful to humans and the environment (Ahrens and Morrisey, 2005). Countries with no domestic production often store coal in stockpiles or storage facilities at ports. An environmental consequence of this type of activity is the presence of coal originating from the spillage from loading/unloading facilities at piers and conveyor belts, emissions from stockpiles (WCA, 2020) caused by wind or water and the resuspension of submerged coal due to swells, among other sources. Despite the developments in control measures to reduce emissions by the mining industry (e.g. using insulated conveyor belts, replacing bulk cargo systems by containers and replacing open stockpiles by pressurized warehouses), incidents where coal is found in the environment are still frequent (Figure 1a).

a)

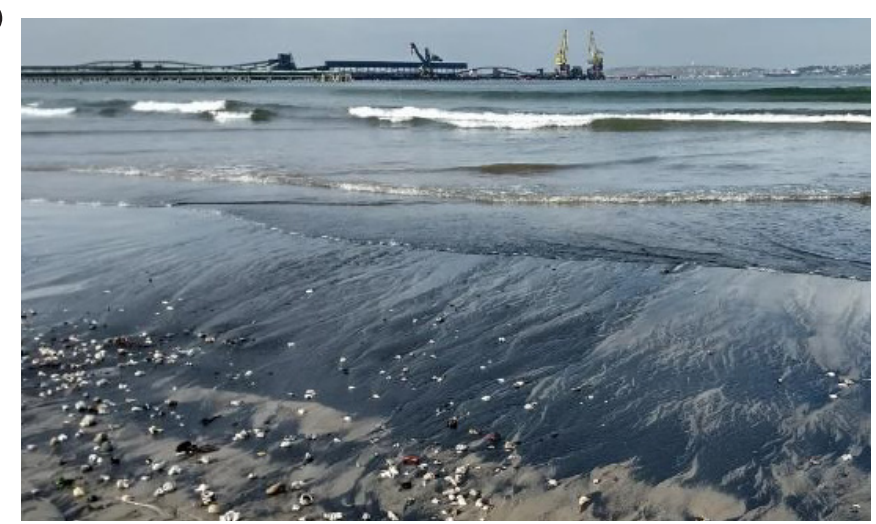

b)

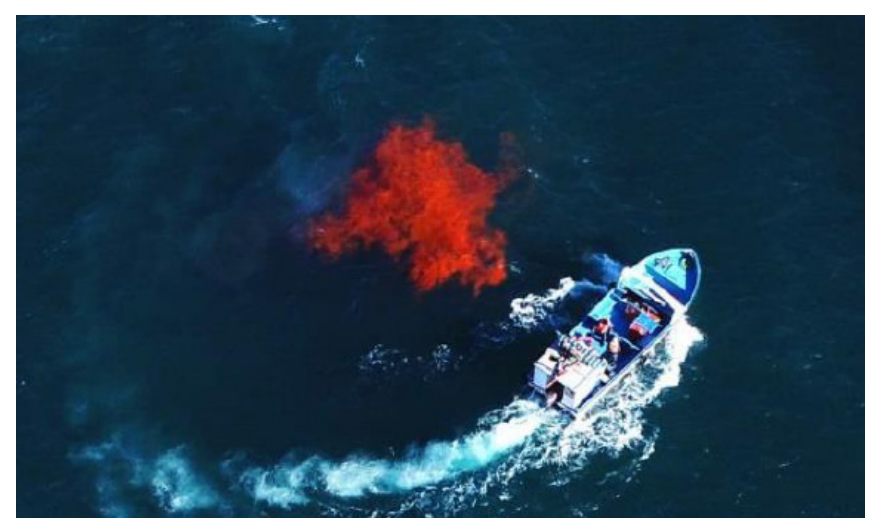

Figure 1: a) Coal found on a beach in Quintero Bay, Chile. The background shows a pier where coal is imported and then stored in a stockpile for power generation and b) a plume of rhodamine used to characterize surface mixing processes during an oceanographic study at the site
Though the biological effects of coal in the marine environment have already been studied (Ahrens and Morrisey, 2005; Franco-Herrera et al., 2011; Berry et al., 2016), the transport processes it experiences in coastal waters has been scarcely examined (e.g. Johnson and Bustin, 2006). The identification of the source of contamination is a complex task that can be approached by a combination of field data characterization of the site and candidate sources (e.g. Franco-Herrera et al., 2011) with hydrodynamic and mixing/transport modeling (e.g. Tang et al., 2006; Rossi et al., 2014). Field data include Eulerian and Lagrangian current measurements, use of tracers and sediment sampling. Modeling the mixing processes affecting liquid substances (e.g. advection, turbulent diffusion, shear dispersion and reaction) and transport processes of granular material such as sedimentation (i.e. the tendency for particles in suspension to settle out of the fluid) and resuspension (i.e. particle remobilization as a consequence of waves or currents), are valuable tools to link source and site effects.

Tracers provide valuable information to characterize nearshore hydrodynamics and calibrate numerical models used to assess the impact of liquid substances such as oil spills, sewage disposal, cooling water systems and brine discharges (James, 2002). Rhodamine is commonly used to characterize mixing properties of water bodies (e.g. Rypina et al., 2021) because it is an easily-accessible substance which generates a marked contrast with water. Moreover, the plume can be traced for several hours and measured from oceanographic vessels (Figure 1b) and jetskis (Clark et al., 2014) or remotely identified by moored balloons (Takewaka et al., 2003), drones and airplanes (Klemas et al., 1974). Flow features inferred from the mixing of rhodamine at the surface, however, do not strictly represent the mixing of liquid substances affected by stratification (e.g. sewage, thermal plumes), those settling to the sea bottom (e.g. brine) or those being mixed in the water column (Fischer et al., 2013).

Liquid tracers have been used to identify sediment transport mechanisms at river mouths (Moritz et al., 2011), estuaries (Royal Haskoning, 2016a) and open coasts (Royal Haskoning, 2016b), or to understand the fate of dredging material deposition (Smith et al., 2007; Vroom et al., 2017). Although rhodamine has been used under the 
assumption that its mixing pattern replicates the transport of granular materials, there is no literature to prove the degree of similarity between those substances at different time and spatial scales. Transport processes of coal include the superficial drift of fine grains, advection and turbulent diffusion of the suspended fraction, and the sedimentation and/or resuspension of deposited particles due to currents and waves. The latter depends on the balance between the vertical diffusion associated with the turbulence and the tendency of the grains to settle due to their weight (Bennett, 1987). Physical modeling on small-scale experiments has been extensively used to study thermal discharges (e.g. Roberts et al., 2011) and dense liquid discharges under a variety of flow conditions (e.g. Gungor and Roberts, 2009; Abessi and Roberts, 2014, 2015; Choi et al., 2015; Daviero and Roberts, 2006, Tian et al., 2004a, 2004b, 2006). All these efforts are based on the pioneering work of Roberts and Tian (2000, 2004), who developed experimental techniques for three-dimensional imaging of plumes.

In this paper we provide a simple, low-cost yet accurate experimental procedure to assess if the mixing of rhodamine can be used to predict the transport of coal in a water current on a model scale.

\section{Materials}

\section{Experimental apparatus}

Experiments were carried out in a $15 \mathrm{~m}$ long, $1.0 \mathrm{~m}$ wide and $1.5 \mathrm{~m}$ deep flume at the Escuela de Ingeniería Civil Oceánica of the Universidad de Valparaíso (Figure 2a). The flume is housed in a dark room, specially designed to reduce interference from environmental light. The flume glass walls allowed optical access to the test section. Water was forced with a $75 \mathrm{Hp}$ Pedrollo pump with a frequency converter to modify the flow rate, and hoses connecting both ends of the flume (Figure 2b). Cartesian coordinates $x, y$ and $z$ are used herein for the stream wise, span wise and vertical coordinates, respectively (Figure 2c).

Tests were carried for a flow rate of $Q=0.0101 \mathrm{~m}^{3} / \mathrm{s}$, corresponding to a bulk mean velocity of $U \approx 50 \mathrm{~mm} / \mathrm{s}$ typically obtained from in situ measurements in Quintero bay. In order to produce a relatively uniform flow in the inlet, two consecutive momentum diffusers (metal grating encasing heterogeneous gravel) were used. A third diffuser was placed at the end of the flume to separate the channel from the outlet. The still water depth was set to $25 \mathrm{~cm}$. Velocity profiles were measured using a NORTEK ADV Vectrino velocimeter mounted on a mobile metal guide that allowed several point-wise measurements on four crosssections ( $y z$-plane) at $x=0,1.73,2.23$ and $5 \mathrm{~m}$, where $x$ $=0$ is the section where liquid solutions of rhodamine and dry samples of coal were released. This origin is located 4 $\mathrm{m}$ downstream from the momentum diffuser. Each pointwise measurement was measured during 10 min allowing to properly capture the mean value, and the records were then filtered using the procedure of Goring and Nikora (2002).

The transport of tracers was recorded with 3 GoPro cameras: from lateral ( $x z$-plane), azimuthal ( $x y$-plane) and perspective views. These cameras provided images with 256 levels in RGB bands with a resolution of $2704 \times 1520$ pixels, at an acquisition frequency of $60 \mathrm{~Hz}$. For each test, lateral and azimuthal videos were analyzed with an image processing algorithm developed for this study. The field of view (FOV) covered a $0.60 \mathrm{~m}$ height and $3 \mathrm{~m}$ long LED screen with a light diffuser which was assembled to generate a uniform and continuous light source, against which the plumes were sharply delineated. The vertical structure of the water temperature showed a homogeneous distribution during the experiments, with temperatures between 16.5 and $17.5^{\circ} \mathrm{C}$. Videos were recorded during $40 \mathrm{~s}$, a time long enough to let the plume exit the FOV.

\section{Coal and rhodamine samples}

A coal sample was obtained from the stockpile of Quintero port. The sample was dried and then graded, showing a wide range of particle sizes. Preliminary tests showed that a marginal fraction of finest grains remained in the surface, mid-size grains were transported in the water column and coarse grains underwent sedimentation without experiencing further resuspension. To better discriminate among these processes, the raw sample was divided into a fine fraction (Coal FF, $d_{50}=0.14 \mathrm{~mm}$ ) and a coarse fraction (Coal CF, $d_{50}=0.54 \mathrm{~mm}$ ) which granulometry is included in Table A1. The division between the samples was arbitrarily defined to be $0.25 \mathrm{~mm}$, corresponding to sieve 60 of the ASTM sieve (ASTM, 2005).

The discharge of substances was located $10 \mathrm{~cm}$ above the still water level at $x=0 \mathrm{~m}$, resembling (but not replicating) 
the spillage of coal from an unloading facility, conveyor belt or due to wind transport from a stockpile. The coal sample was encased in a cylindrical dispenser with a moving lid at its bottom which was instantaneously opened by releasing an extended spring. For each test, $10 \mathrm{~g}$ of coal measured on a digital scale with ant accuracy of $0.01 \mathrm{~g}$, were placed in the dispenser.

For Rhodamine, an $80 \mathrm{~g}$ solution supplied by Abbey Color ${ }^{\circledR}$ was dissolved in $1 \mathrm{~L}$ of ethyl alcohol, and subsequently diluted in $10 \mathrm{~L}$ of fresh water. The concentration of $1100 \mathrm{mg} / \mathrm{L}$ achieved was enough to provide a sharp contrast with the background. Rhodamine was released at room temperature to minimize buoyant effects. A peristaltic pump (ETATRON B3-V-4-3 model) working at a flow rate of $4 \mathrm{~L} / \mathrm{h}$ at 3 Bar pumped during $5 \mathrm{~s}$ from the same point of the dispenser's bottom lid. For sake of visualization, Figure 3 shows the overlap of rhodamine and coal experiments (images in pixels before scaling to $\mathrm{cm})$ at two distinct times where it is visible the cigar shape of the rhodamine induced by its pumping mechanism ( $t=$ $2 \mathrm{~s})$ and the coal deposition is clearly visible at $(t=14 \mathrm{~s})$. It is also clear that at this latter time, rhodamine and coal plumes follow similar paths.

a)

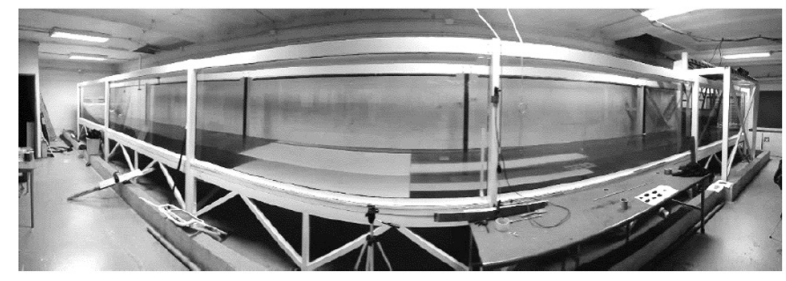

b)

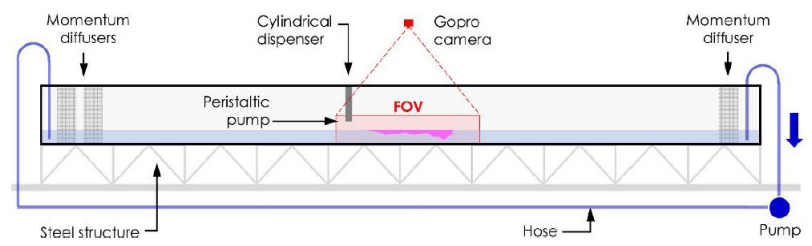

c)

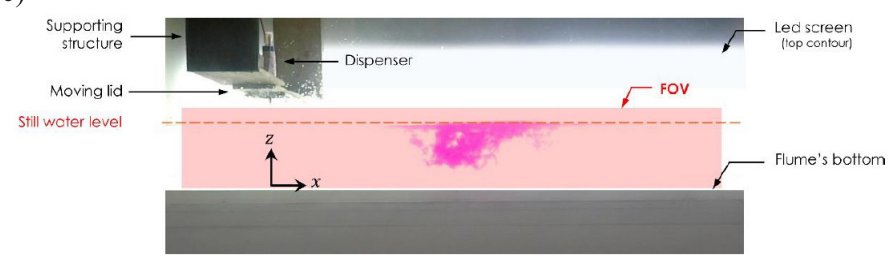

Figure 2: a) Side view of the flume at the School of Ocean Engineering of the Universidad de Valparaíso, b) sketch of the experimental apparatus and c) details of the sampling section with the led screen and the field of view. The coordinate system is included. a)

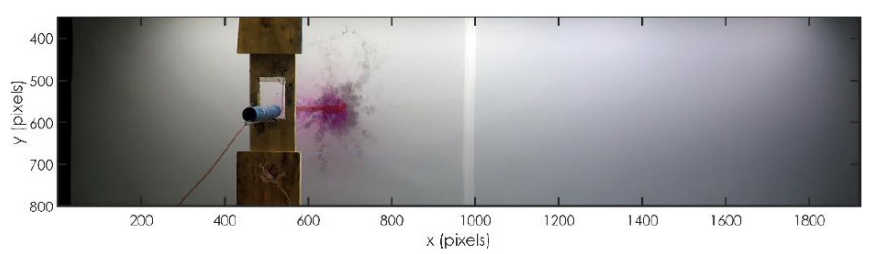

b)

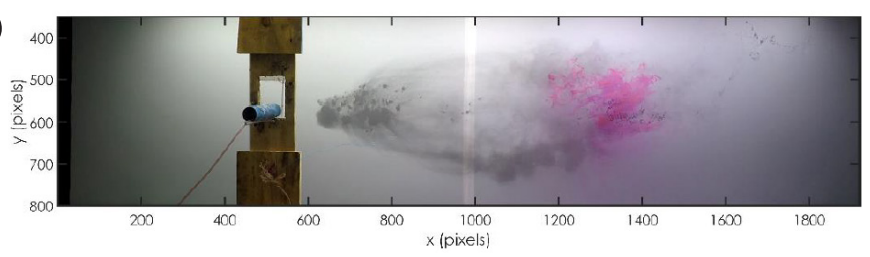

Figure 3: Azimuthal view of experiments of rhodamine (red plume) and coarse coal (dark plume). The images result from the overlap of snapshots obtained for both substances at (a) $t=2 \mathrm{~s}$ and (b) $t=14 \mathrm{~s}$. Images are depicted in pixels before scaling to $\mathrm{cm}$.

\section{Methods}

\section{Image processing}

Imaging methods have proven to be useful in different fields of hydraulics and fluid mechanics, enabling measurement of flow variables in a non-intrusive way with high spatial and time resolution (Tropea and Yarin, 2007; Lin et al., 2012). In this study, imaging techniques were used to determine the plume's shape and evolution, as a simple way to compare the mixing of rhodamine and transport of coal. In doing so, the pixel intensity was used as a proxy for the concentration. An image processing algorithm in Matlab ${ }^{\circledR}$ was developed to delimit the plume's geometry and concentration in videos obtained from the azimuthal and lateral views. The first step of this procedure consisted in obtaining a background image by averaging 5 frames before releasing the tracer. This background was then subtracted from each image to enhance the plume contrast. Pixels belonging to the plume were defined when the intensity of the raw image (Figure 4a) subtracted by the background, exceeded a threshold of 15 (in the grey scale 0 to 255). This yielded a binary image per frame (Figure $4 b$ ). The threshold was preliminary defined from the analysis of videos, by checking if the computed shape of the plume was consistent with the one identified by visual inspection. The detection algorithm was built to consider cases where the rhodamine was divided due to entrainment in smaller fractions (Figure 4c) or by sedimentation in the case of coal (Figure 4d), in which case only the downstream moving portion was considered. The determined relevant geometric parameters of the plume in pixel scale, namely 
the area and the plume's centroid, and then scaled to physical units.

a)

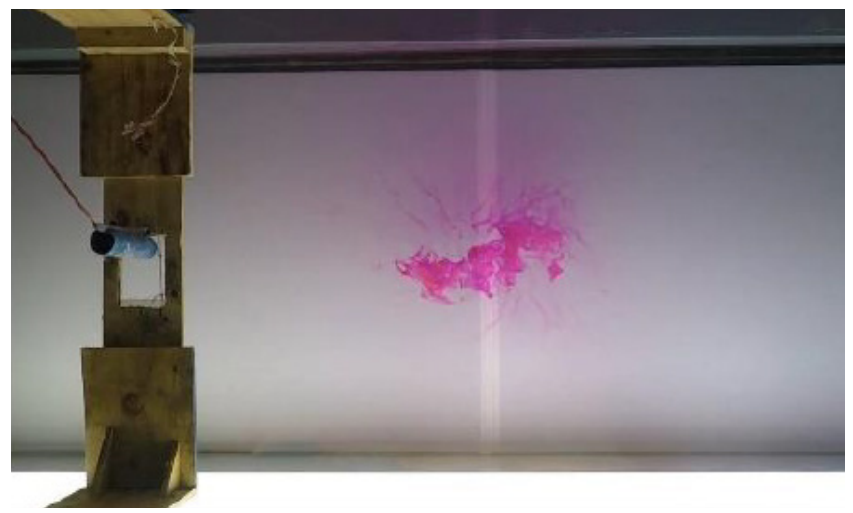

b)

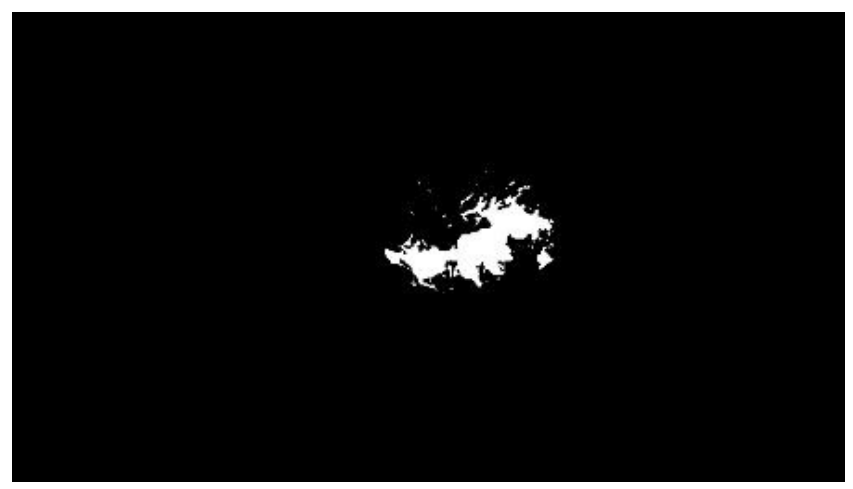

c)

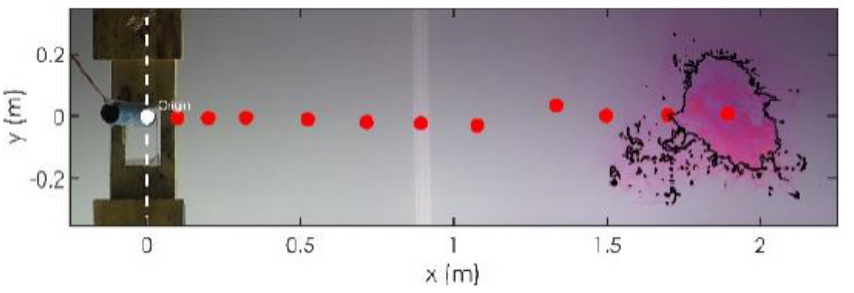

d)

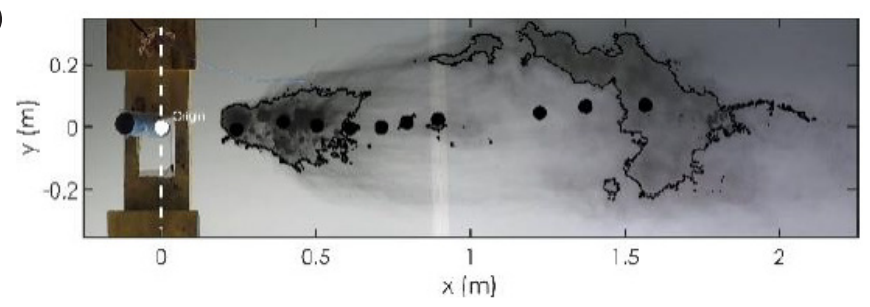

Figure 4: Illustration of the plume detection algorithm. (a) Original image extracted from the video, (b) binary image defined by a given threshold. Trajectories of the plume centers of (c) rhodamine and (d) coal.

\section{Modeling cases}

The notation $S_{j} R_{k} O_{l}$ was introduced to identify tests, where $S_{j}$ represents the substance $\left(S_{1}\right.$ : rhodamine, $S_{2}$ : coal $\mathrm{FF}, S_{3}$ : coal CF), $R_{k}$ is the repetition $(k=1,2,3)$ and $O_{l}$ the viewpoint $\left(O_{1}\right.$ : lateral, $O_{2}$ : azimuthal). The plume was characterized by the area $A\left(S_{j}, R_{k}, O_{l}, t\right)$, in $\mathrm{cm}^{2}$, and the position of its centroid $X c\left(S_{j}, R_{k}, O_{l}, t\right)$, in cm for all possible combinations of substance, repetition and viewpoint. For example, $A\left(S_{2}, R_{3}, O_{2}, t\right)$ represents the area of the fine fraction of coal, viewed from the lateral view at time in the third repetition. These parameters were calculated every $0.1668 \mathrm{~s}$ and filtered with a moving average of 9 steps $(1.5012 \mathrm{~s})$ to smooth out small scale turbulent fluctuations. The discharge corresponds to $t=0 \mathrm{~s}$. The time evolution of the plume's centroid $X c$ and area $A$ were used as indicators of advection and turbulent diffusion experienced by the substance, respectively. Three repetitions were performed for each substance at exactly similar conditions to assess the randomness of the mixing process.

\section{Quantitative comparison of rhodamine and coal from bulk properties}

A simple quantitative criterion was used to define if rhodamine could adequately predict the behavior of coal. For tests with the same conditions, the ratio between the values of each variable obtained for each substance at 4 instants $t_{k}(k=1,2,3,4)$ was computed (Figure 5). If the ratio was in the range $0.8<r<1.2$, both substances were considered to have a similar behavior at instant $t_{k}$; otherwise not. As example, Figure 5 depicts the selection of four values for the plume's area computed from the lateral view for cases $S_{1} R_{2} O_{1}$ (rhodamine) and $S_{2} R_{1} O_{1}$ (coal FF). Clearly for $t_{l}=5 \mathrm{~s}$, both substances do not show similar behavior while for the other times they do. Though this range was arbitrary defined, sensitivity analyses proved results were not significantly sensitive to it.

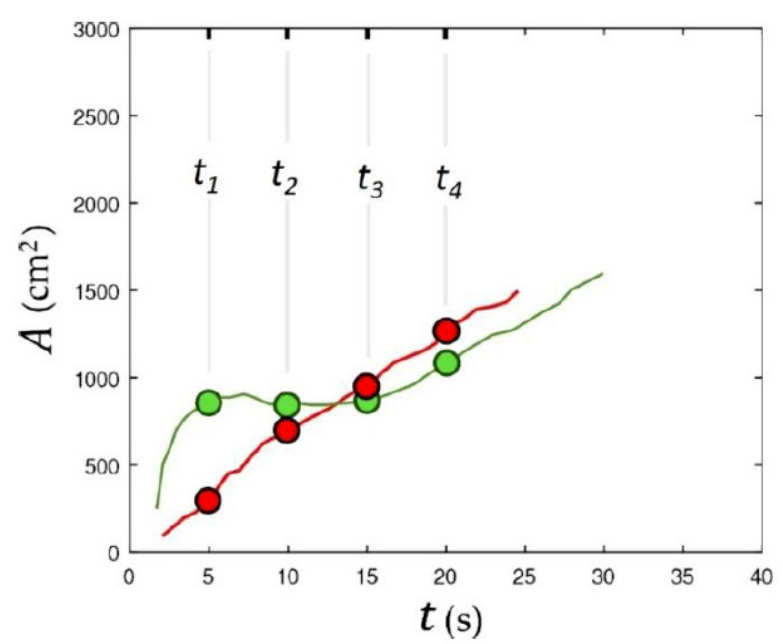

Figure 5: Example of comparison between area of rhodamine and coal FF from the lateral view, at 4 different times after the discharge. Red, green and black lines represent repetitions of rhodamine, coal FF and coal $\mathrm{CF}$, respectively. Each curve is computed until the plume reaches the boundary of the FOV. 


\section{Quantitative comparison of rhodamine and coal from concentration profiles}

Concentration profiles for rhodamine and coal at different sections and repetitions were analyzed and compared to theoretical profiles of sediment concentration on a fully developed turbulent flow. To do so, the pixel intensity was used as proxy of the concentration of rhodamine and coal, with no further calibration. Under a fully developed turbulent flow, the interaction between the sediment depositional dynamics and the upward diffusion due to turbulent eddies determines the region where it is preferentially transported (Vanoni, 1975). For flows carrying low amount of sediment, the local average concentration can be estimated with the formula of Rouse (1937), stemming from the balance of the gravitational settling of particles and the upward diffusive flux due to turbulence (Jha and Bombardelli, 2010). The local average concentration at elevation $z$ is given by

$$
C_{S}(z)=C_{S a}\left(\frac{h-z}{z} \cdot \frac{a}{h-a}\right)^{R o}
$$

where $C_{s a}$ is the mean solute concentration at a conventional elevation (typically $a=0.05 h$ ), Ro is the Rouse number defined as $R o=w_{s} / \beta \kappa u_{*}$ (Julien, 2010; Dey, 2014), $w_{s}$ was determined using the formula of Dietrich (1982), which has been evaluated in previous studies for similar ranges of Reynolds number and grain size distribution (Jha and Bombardelli, 2010; Muste et al., 2005) and $\kappa$ is the von Karman constant $(\kappa=0.41)$. The parameter $\beta$ is a depth average attenuation coefficient defined as $\beta=$ $1 / S c_{t}=\varepsilon_{\mathrm{s}} / \varepsilon_{\mathrm{t}}$, which relates solute and momentum diffusion coefficients; it is generally assumed to be 1.0 (Muste et al., 2005). Coleman (1970) proposes a correction $\beta$ for when turbulence has a predominating influence $\left(w_{s} / u_{*}<1\right)$ over gravitational settling

$$
\beta\left(0.1<\frac{w_{s}}{u_{*}}<1\right)=1+2\left(\frac{w_{s}}{u_{*}}\right)^{2}
$$

In the case of coarse coal, where the bed load transport is dominant, the sediment concentration near the bed is calculated using a simplification of Rouse equation assuming $h-z \approx h-a$ (Julien, 2010). Flow characteristics of the experiment and suspension parameters are summarized in Table A2.

\section{Results \\ Flow dynamics}

The hydrodynamic condition tested was defined by a flow rate of $\mathrm{Q}=0.0101 \mathrm{~m}^{3} \mathrm{~s}^{-1}$, a Reynolds number of $\mathrm{Re}=2.7 \times$ $10^{4}$ and a Froude number of $\mathrm{Fr}=0.03$. The velocity profiles, turbulent intensities and Reynolds stresses measured at sections $x=0 \mathrm{~m}, 1.73 \mathrm{~m}, 2.23 \mathrm{~m}$ and $5 \mathrm{~m}$ are shown in Figure 6 . The flow is a typical boundary layer flow with a mean $\mathrm{u}^{*}=0.0026 \mathrm{~m} / \mathrm{s}$. a)

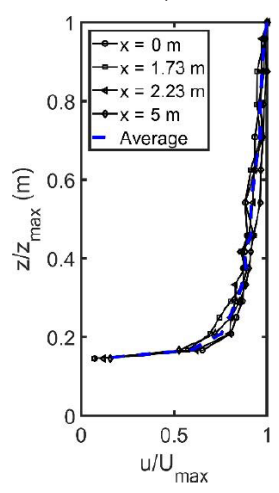

b)

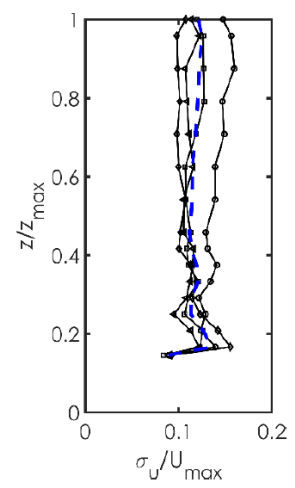

c)

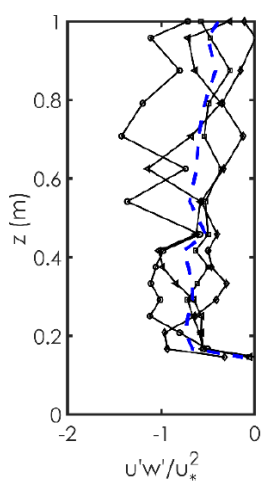

Figure 6: Characterization of the flow at different sections for condition Q1: (a) mean velocity profiles, (b) root-mean-square of the velocity and (c) Reynolds stresses

\section{Qualitative description of mixing of rhodamine and coal transport}

The analysis of lateral videos at different instants and different sections shows that rhodamine, coal FF and coal CF behave differently when transported by a flow. The mixing of the plume of rhodamine (Figure 7) is controlled by advection close to the free surface, with minor vertical and horizontal diffusion. The plume's length of $\approx 25 \mathrm{~cm}$ observed after $t=7.0 \mathrm{~s}$ is explained by the bursts of rhodamine injected by the peristaltic pump during $5 \mathrm{~s}$, thus forming an elongated and irregular plume. The vertical momentum from the release $10 \mathrm{~cm}$ above the still water level seems minor. Further downstream, there is some water entrainment into the plume, but its shape remains reasonably stable along the flume. Additionally, there is a very low-concentration fraction of rhodamine diffusing rapidly in the surface (probably related to chemical reactions between the colored solution and water), which is not observed in the lateral view (as its concentration remains below the threshold). 
Winckler, P., Molteni, F., Reyes, M., Gubler, A., Sandoval, J. and Aleixo, R. (2021). Is Rhodamine a good tracer to predict coal transport in water?. Obras y Proyectos 30, 16-29

The transport of Coal FF includes different processes occurring at different times and locations (Figure 8). Immediately after the instantaneous release, coal is wetted as the bulk grains entrains water. From time $t=0$ to $t=$ $3.5 \mathrm{~s}$, coal is advected close to the free surface, however, its weight and vertical momentum transport mix the substance, until occupying the water column $(t=7.0 \mathrm{~s})$. Between $t=10.5$ and $13.7 \mathrm{~s}$, advection is not uniform and begins to be influenced by the mean flow velocity profile and by the falling velocity of the fine coal. From $t=17.0$ $\mathrm{s}$ onwards, the grains remain in the lower part of the water column, resembling a gravity current. Given this behavior, two regions are identified. The near-field correspond to the region where the effect of the discharge and the fall velocity of coal play an important role. Here, the mixing process is governed by the self-induced turbulence generated by the discharge near the surface. This vertical momentum from the discharge entrains water, resulting in rapid mixing which tends to decay with distance, as a gradual transition
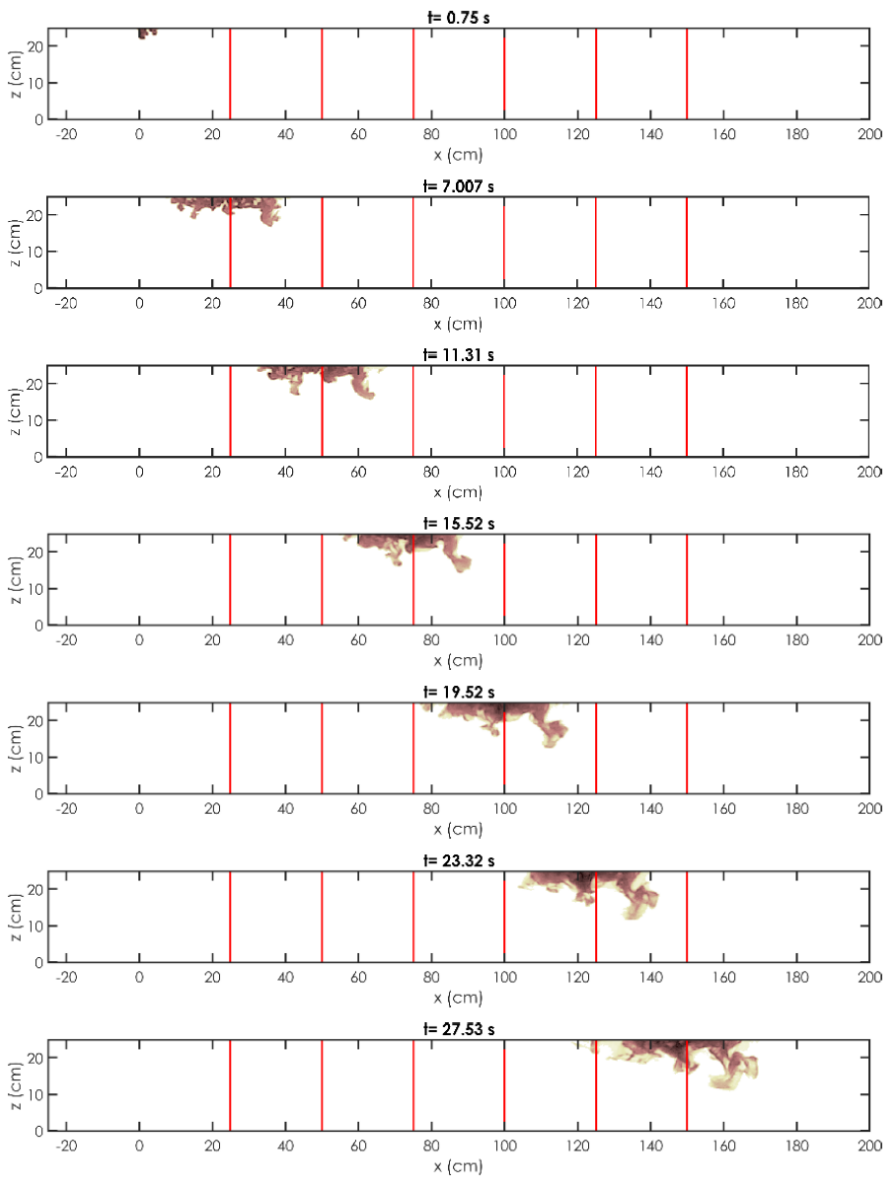

Figure 7: Evolution of the rhodamine plume in the channel, for case $S_{1} R_{1} O_{1}$. Red lines depict sections where ensemble concentration profiles are analyzed (Figure 12) to horizontal flow is observed. The far-field, on the other hand, is the region where the effects of the discharge is no longer relevant, and the transport is controlled by the background flow. From Figure 8 it is possible to estimate that the near-field holds up to about $17 \mathrm{~s}$.

For Coal CF (Figure 9) there is a quick deposition of the coal and two driving mechanisms acting thereafter: the deposition of the coarser grains of coal and its advection downstream. As for the fine fraction, its transport also shows near- and far-field regimes controlled by the source and the background flow, respectively. The near-field, however, extends for a smaller time $(t=4.2 \mathrm{~s})$, after which the plume is transported as a density current like flow. Due to the entrainment, the plume grows in size after $t=4.2 \mathrm{~s}$, nearly reaching the free surface. There is a considerable fraction of coarse grains (not observed in this lateral view) that remains in the bottom, leaving a well-defined trail as coarse grains settle without resuspension.
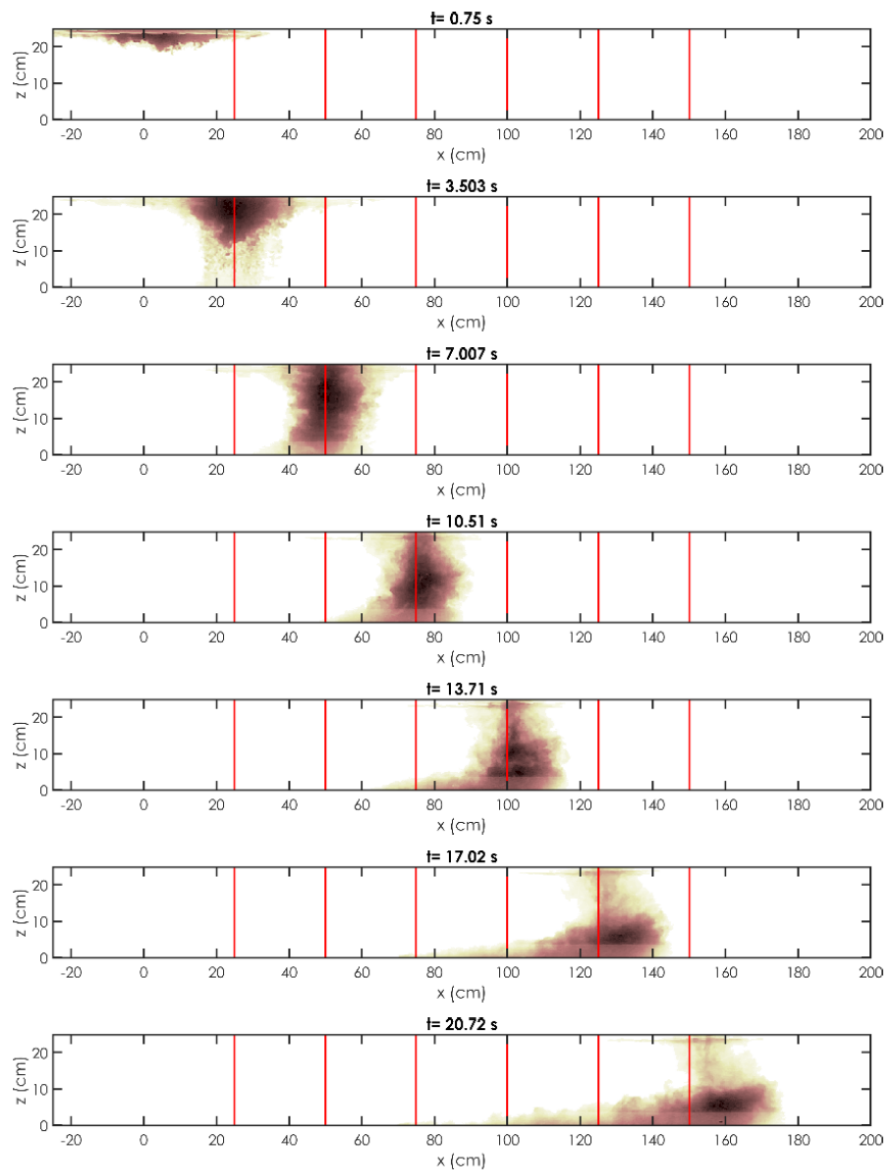

Figure 8: Evolution of the fine coal plume (FF) in the channel, for case $S_{1} R_{1} O_{1}$. Red lines depict sections where ensemble concentration profiles are analyzed (Figure 12) 

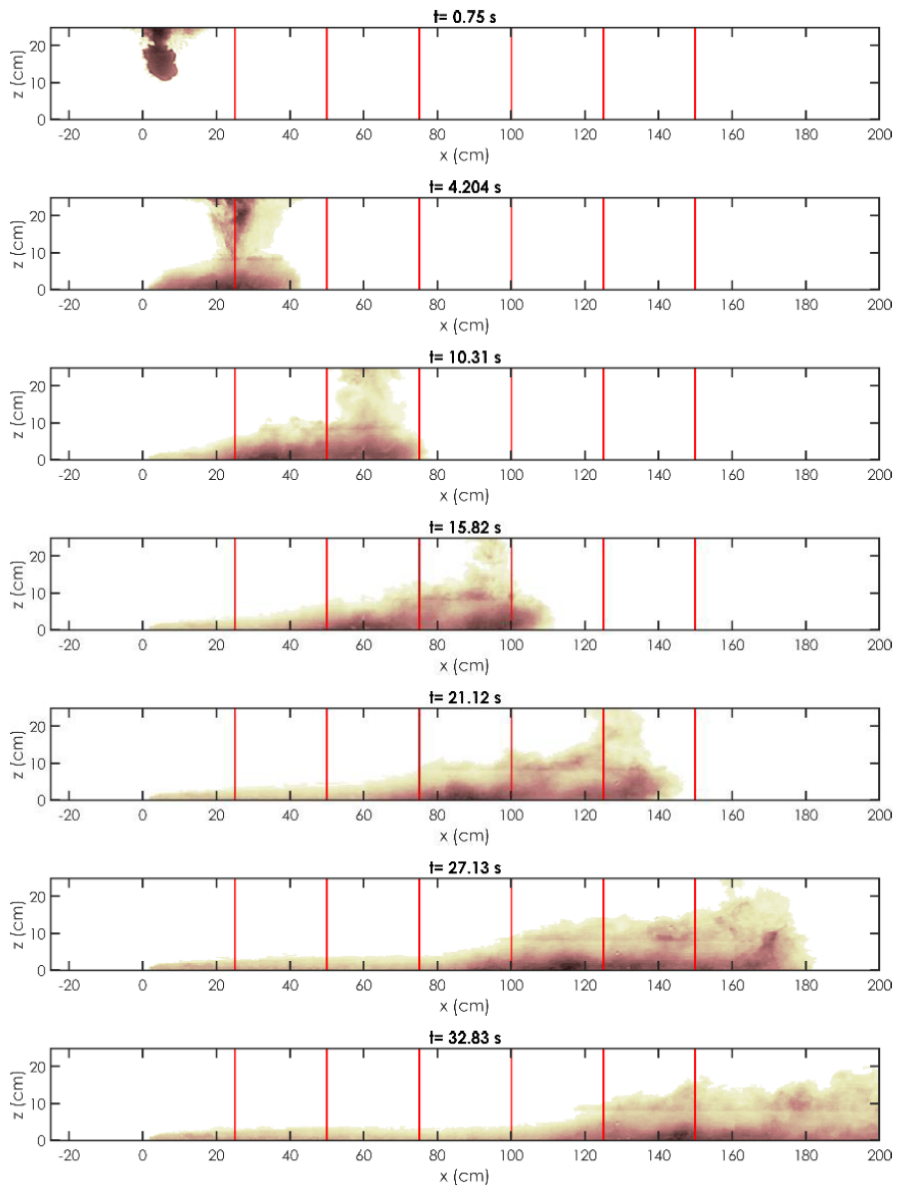

Figure 9: Evolution of the coarse coal plume (CF) in the channel, for case $S_{1} R_{1} O_{1}$. Red lines depict sections where ensemble concentration profiles are analyzed (Figure 12)

\section{Quantitative comparison of rhodamine and coal from} bulk properties

The comparison of the plume's area $A$ and the position of its centroid $X_{c}$ for all possible combinations of substance, repetition and viewpoints is depicted in Figure 10. From these figures, the quantitative criterion included in the section of methods is used to define if rhodamine can adequately predict the behavior of both fractions of coal. These results, shown in Table 1, first represent the percentage of cases in which each parameter is adequately predicted by each repetition of rhodamine $\left(S_{1} R_{\mathrm{i}}, i=1,2,3\right)$. Then, these values per repetitions are averaged and then averaged by point of view. Overall, it is observed that the plume's area of rhodamine is a bad predictor of coal FF (25\% of cases) and ever worse for coal CF (11\%). This is explained by the fact that the area of the plume of rhodamine is significantly smaller than for coal samples, especially for the azimuthal view (Figure 10a,b). In contrast, for the plume's centroid, adequately predicts $88 \%$ and $89 \%$ percentages of the cases of coal FF and coal CF, respectively. This is observed by the similitude trajectories shown by all three substances (Figure 10c,d), which are controlled by the advection of the mean flow. The outstanding results for coal CF, however, overshadow the fact that a significant portion of the coarse grains settle down without resuspension. In simple terms, rhodamine is a good predictor of the advection of the suspended grains of coal (for both fractions) but fail to represent the growth of the coal plume, triggered by turbulent diffusion. Finally, sedimentation is completely overlooked by this procedure. a)

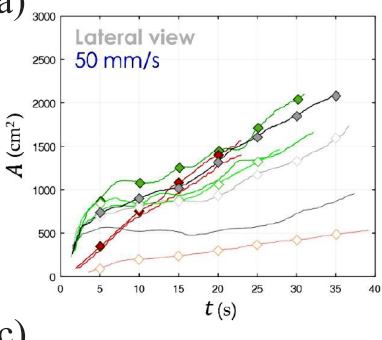

c)

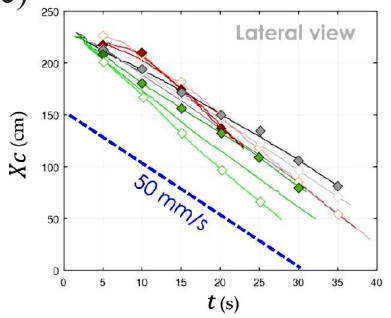

b)

d)

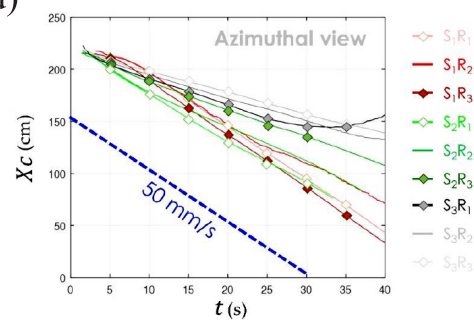

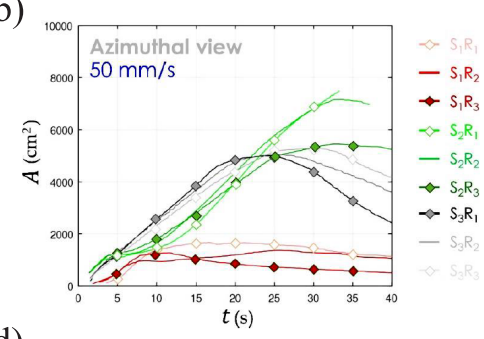

Figure 10: Area of the plume $A$ computed from the (a) lateral and (b) azimuthal views. Centroid of the plume $X_{c}$ computed from the (c) lateral and (d) azimuthal views. The mean velocity of $U \approx 50 \mathrm{~mm} / \mathrm{s}$ is represented in blue dashed lines. In both panels, red lines correspond to Rhodamine $\left(S_{1}\right)$, green lines to coal FF $\left(S_{2}\right)$ and grey lines to coal CF $\left(S_{3}\right)$ for all repetitions $R_{i}(i=1,2$, $3)$. Each curve is computed until the plume reaches the boundary of the FOV.

Table 1: Percentage of cases in which rhodamine predicts the plume's area $A$ and centroid

\begin{tabular}{|c|c|c|c|c|c|c|c|c|}
\hline \multirow{3}{*}{ Test } & \multicolumn{4}{|c|}{$\begin{array}{c}\text { Compared with coal FF } \\
\left(S_{2}\right)\end{array}$} & \multicolumn{4}{c|}{$\begin{array}{c}\text { Compared with coal CF } \\
\left(S_{3}\right)\end{array}$} \\
\cline { 2 - 9 } & \multicolumn{3}{|c|}{ Lateral view } & $\begin{array}{c}\text { Azimuthal } \\
\text { view }\end{array}$ & \multicolumn{2}{c|}{ Lateral view } & \multicolumn{2}{c|}{$\begin{array}{c}\text { Azimuthal } \\
\text { view }\end{array}$} \\
\cline { 2 - 9 } & $A$ & $X_{c}$ & $A$ & $X_{c}$ & $A$ & $X_{c}$ & $A$ & $X_{c}$ \\
\hline \multirow{2}{*}{$\begin{array}{l}S_{1} R_{1} \\
S_{1} R_{2} \\
S_{1} R_{3}\end{array}$} & 0 & 83 & 33 & 100 & 0 & 100 & 0 & 75 \\
\cline { 2 - 9 } & 33 & 67 & 0 & 100 & 33 & 100 & 0 & 75 \\
\hline $\begin{array}{c}\text { Averaging } \\
\text { repetitions }\end{array}$ & 33 & 75 & 17 & 100 & 22 & 100 & 0 & 78 \\
\hline $\begin{array}{c}\text { Averaging } \\
\text { views }\end{array}$ & & & 25 & 88 & & & 11 & 89 \\
\hline
\end{tabular}


Figure 10 shows that there is a significant variability in the estimation of the plume's area $A$ for coal samples while the position of the centroid $X_{c}$ follows minor changes among repetitions. This variability can be attributed to the natural randomness of the turbulent flow field and to experimental errors. To assess the variability within repetitions of coal samples, Table 2 shows the percentage of cases in which one repetition follows the same behavior of the others, following the quantitative criterion included in the section of methods. It is observed that the position of the centroid $X_{c}$ has a relatively high repetition for coal FF (92\%) and no variability for coal CF $(100 \%)$, the latter which can be argued by case $S_{3} R_{1}$, which begins to deviate after $t$ $=35 \mathrm{~s}$ (Figure 10d). The area $A$ has larger but still minor variability among repetitions, explained by the large changes in the lateral view (Figure 10a).

Table 2: Percentage of cases in which coal sample (FF and CF) are compared to different repetition

\begin{tabular}{|c|c|c|c|c|c|c|c|c|}
\hline \multirow{3}{*}{ Test } & \multicolumn{4}{|c|}{$\begin{array}{l}\text { Compared with coal FF } \\
\qquad\left(S_{2}\right)\end{array}$} & \multicolumn{4}{|c|}{$\begin{array}{l}\text { Compared with coal CF } \\
\left(S_{3}\right)\end{array}$} \\
\hline & \multicolumn{2}{|c|}{$\begin{array}{l}\text { Lateral } \\
\text { view }\end{array}$} & \multicolumn{2}{|c|}{$\begin{array}{l}\text { Azimuthal } \\
\text { view }\end{array}$} & \multicolumn{2}{|c|}{ Lateral view } & \multicolumn{2}{|c|}{$\begin{array}{l}\text { Azimuthal } \\
\text { view }\end{array}$} \\
\hline & $A$ & $X_{c}$ & $A$ & $X_{c}$ & $A$ & $X_{c}$ & $A$ & $X_{c}$ \\
\hline \multirow{3}{*}{$\begin{array}{l}S_{2} R_{1} \\
S_{2} R_{2} \\
S_{2} R_{3} \\
\end{array}$} & 75 & 92 & 92 & 92 & & & & \\
\hline & 83 & 92 & 100 & 100 & & & & \\
\hline & 50 & 83 & 92 & 92 & & & & \\
\hline \multirow{3}{*}{$\begin{array}{l}S_{3} R_{1} \\
S_{3} R_{2} \\
S_{3} R_{3}\end{array}$} & & & & & 50 & 100 & 100 & 100 \\
\hline & & & & & 33 & 100 & 100 & 100 \\
\hline & & & & & 50 & 100 & 100 & 100 \\
\hline $\begin{array}{l}\text { Averaging } \\
\text { repetitions }\end{array}$ & 69 & 89 & 94 & 94 & 44 & 100 & 100 & 100 \\
\hline $\begin{array}{c}\text { Averaging } \\
\text { views }\end{array}$ & & & 82 & 92 & & & 72 & 100 \\
\hline
\end{tabular}

\section{Quantitative comparison of rhodamine and coal from concentration profiles}

Normalized concentration profiles at sections $x=0,0.25$, $0.5,0.75,1.0,1.25$ and $1.5 \mathrm{~m}$ were determined for each repetition and then ensemble-averaged for each substance. To do this, a $4 \mathrm{~cm}$ width interval was chosen around each section to perform a spatial average (e.g. the measured profile at $x=0.25$ is a spatial average in the interval $0.23<$ $x<0.27 \mathrm{~m}$ ). Finally, an ensemble averaged was performed with all three runs. Figure 11 depicts the three runs with a large variation, and the ensemble average profile for coal $\mathrm{FF}$ as an example of application of this procedure. It is clearly observed that three runs are not enough to ensure that the ensemble average converges, but it allows to smooth some of the existing noise. It is also possible to see that the Rouse profile is not yet suitable to describe the concentration profile, since its required conditions are not met (e.g. suspended transport in equilibrium conditions, considering the channel bed as sediment source). It is also worth mentioning that, due to the blurred glass, close to the bed, the evaluation of the concentration below $z / z_{\max }<0.15$ is not accurate.

In Figure 12, the ensemble average of the three substances is plotted at the aforementioned locations. It can be seen that, whereas higher concentration values are found for coal (FF and $\mathrm{CF}$ ) closer to the channel bed, the rhodamine is transported closer to the free surface. At distances larger than $x>75 \mathrm{~cm}$, coal profiles tend to be quite similar. All these patterns were already observed in Figure 7 to Figure 9.

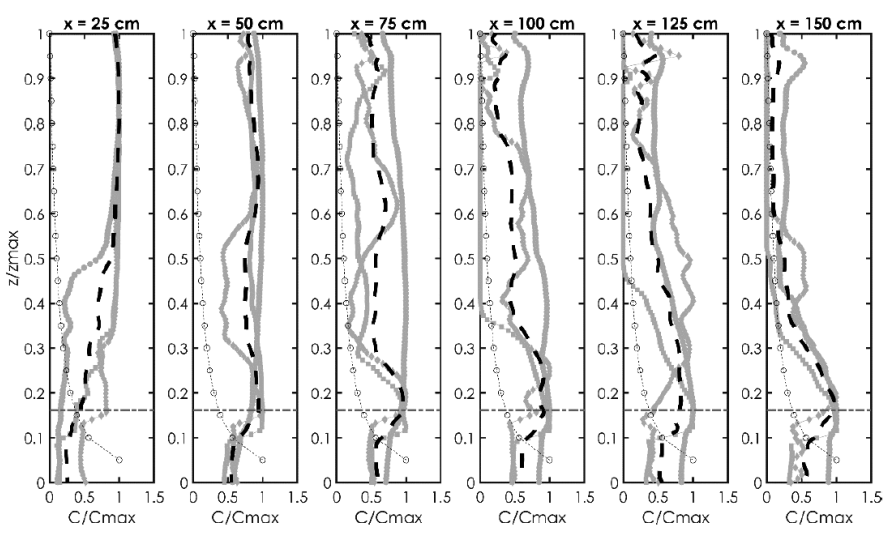

Figure 11: Coal FF concentration profiles at different sections. Grey dotted lines indicate individual runs whereas, black dashed lines depict ensemble averages. Grey dot-lines with circles depict the Rouse profile. Grey dashed line at $z / z_{\max }<0.15$ indicates the limit of the blurred channel glass that prevented accurate measurement of the light intensity
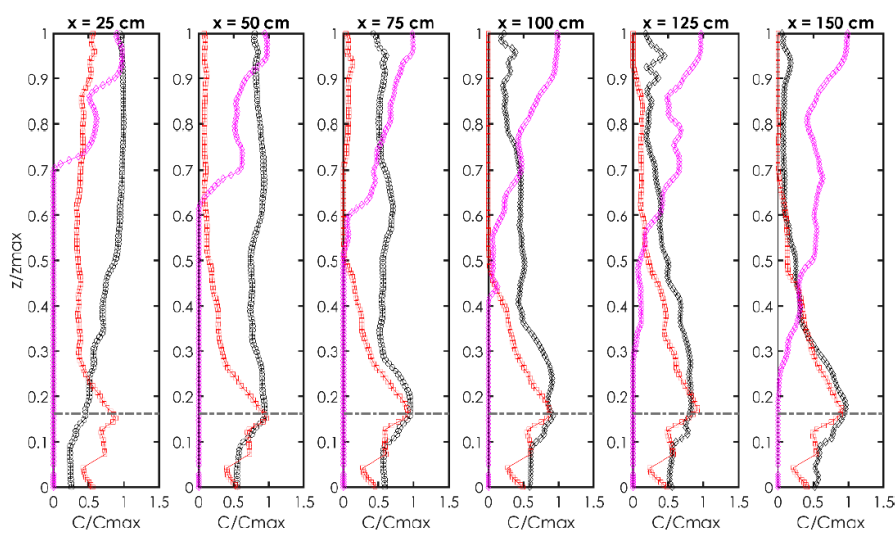

Figure 12: Ensemble averages of each material. Black: coal FF; red: coal CF; magenta: rhodamine. Grey dashed line indicates the limit of the blurred channel glass that prevented accurate measurement of the light intensity 


\section{Discussion}

To discuss whether rhodamine is a good tracer to predict coal transport in water, one must look at different variables in different time and spatial scales. The combination of bulk properties (plume's area and position of its centroid $X_{c}$ ) and concentration profiles used herein provide valuable insights for determining similarities and differences in mixing and transport mechanisms between these substances. From a macroscale perspective, it is observed that, despite the initial effect of the substance input method for rhodamine and coal, as the plumes are advected downstream and entrain water, they tend to mix and dilute, until their shape becomes independent of their initial shape. Due to the lack of whole field measurement techniques (e.g. PIV) that would allow resolving the flow field both in space and in time, a visual classification based on the plume shape depicted in Figures 7-9 was used. This criterion was based on the vertical distribution of coal, being considered that the near-field ended when the coal flowed mainly close to the bed. For both substances, the identified near- and far-field regimes showed different features. Whereas in the near-field, the input mechanism determined the plume's geometry (e.g. cigar-shaped rhodamine plume and vertically distributed coal plume), in the far-field, concurrent mechanisms for both fractions of coal (deposition of the heavier lumps of coal, water entrainment and consequent mixing) made their plumes behave similarly downstream (Figure 12), but with differences in plume sizes (Figure 10a,b).

Another macroscale analysis concerned the trajectory of the plumes. As seen in Figure $4 \mathrm{~d}$ and $4 \mathrm{e}$, the plume of rhodamine stayed more coherent, whereas a plume detachment was observed for coal due to the deposition of coarser grains close to the source. Though the coal plume increased and widened more than rhodamine, within the FOV, the trajectories of their centroids $X_{c}$ were similar (Figure 10c, d and Figure 13). The similarity observed in the evolution of the plume's centroid for both rhodamine and coal is explained by the fact that this variable is controlled by the mean flow advection and weakly affected by the substance's properties, as coal remains suspended in low concentrations. On the other hand, large discrepancies observed in plumes areas, depicts the influence of the substance's physical properties on transverse/vertical diffusion and shear dispersion due to changes in the vertical profile of velocity. These differences observed in the evolution of plume's area between substances, is also explained by both the inertial entrainment of coal in water and the consequent self-induced turbulence that enhance its mixing in the near-field, and the gradual deposition of the coal grains as the plume is advected in the far-field.

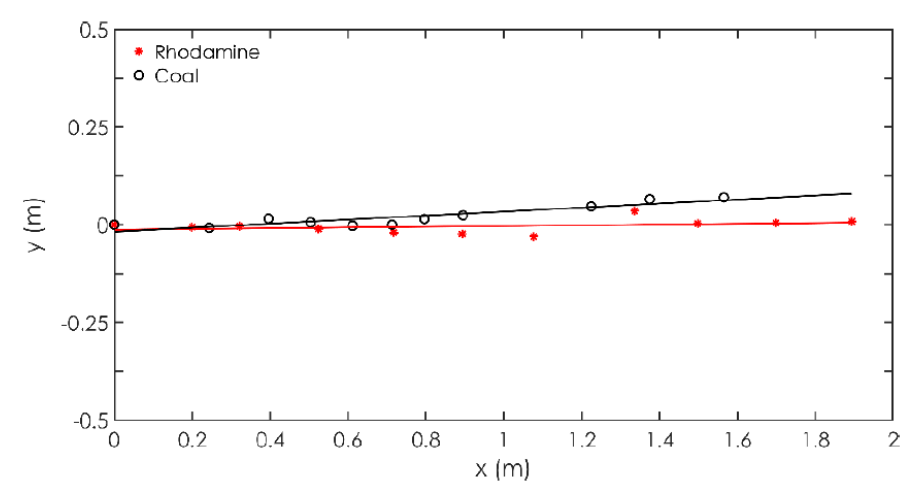

Figure 13: Trajectories of rhodamine $\left(S_{1} R_{1} O_{2}\right)$ and coal $\mathrm{CF}$ $\left(S_{3} R_{1} O_{2}\right)$, as obtained from the azimuthal views in Figure $4 \mathrm{~d}$ and $4 \mathrm{e}$, respectively. For these two repetitions, the measured slope was 0.011 and 0.06 and the celerity of for rhodamine and coal, respectively

Considering the aspects discussed above, it is reasonable to assume that rhodamine can be used to track the suspended particles of coal on a laboratory scale. However, the proposed procedure presents several limitations if aimed to understand the transport of coal in real-scale cases, which are here discussed. In terms of the hydrodynamics, for example, thermal and density stratification, negligible in the analyzed models, may be relevant in the transport of coal and mixing of rhodamine on a particular site, especially during warm days in summer. The fate of these substances could also be affected by rain, flow disturbances by outfalls or density currents from nearby rivers; all of which are omitted herein. Additionally, the essentially 2D velocity profiles achieved in the experiments (Figure 6a) may substantially differ from in situ records, where currents may be highly 3D and affected by the complex hydrodynamics of breaking waves (e.g. undertow) when approaching the coast. Regardless of the complexities of the flow in real cases, we may assume that rhodamine and the finest fractions of coal would behave in the same manner under the same conditions. In other terms, the relatively small size of the FOV limited the understanding of far-field processes, i.e. those which become independent of the discharge. The study of these processes require 
larger spatial scales and longer time scales which could be addressed by scaling up these experiments in a larger flume or complementing models with field experiments comparing simultaneously the fate of rhodamine and coal in coastal waters.

Another limitation is related to the image processing algorithm specially developed for these experiments. Sources of image distortion due to physical processes (e.g. refraction of light propagating through water, glass and air) and geometrical nature (e.g. analyzing an essentially 3D phenomena with two orthogonal images) were not considered in the algorithm. However, the distance at which the cameras where placed with respect to the FOV make us conjecture the distortion is minor compared to the size and shape of the analyzed plumes. Besides, the distortion is present in all images, so it does not alter the comparison among tests.

The analysis performed for the FOV overshadows the behavior of some processes, such as the sedimentation of coal (only captured in the azimuthal view) and the rapid diffusion of a thin rhodamine layer in the surface (only observed, but not accounted in the algorithm). Finally, a lack of a proper color calibration prevented the conversion of the pixel intensity into concentration values.

Improvements to better understand the physics of coal transport phenomena could be achieved by separating raw samples into finer separations. Indeed, the use of an arbitrary threshold of $0.25 \mathrm{~mm}$ between the coal FF and CF did not allow a sharp distinction of the dominant mixing processes affecting different grain sizes. Additionally, better triggering mechanisms for the discharge of rhodamine (liquid) and coal (granular) should be developed to ensure that the relevant properties of the discharge (e.g. mass, vertical momentum, concentration) are comparable. With suitable measurements techniques, such as LIFPIV it would be possible to measure the velocity field and concentration map within the plume and to better characterize the plume-water interaction. In terms of the vertical concentration profiles, discrepancies between theoretical Rouse and observed concentration profiles can be partly explained by the fact that testing FOV is not enough to reach a fully developed turbulent flow. From the perspective of measurements, the use of 3 samples to compare bulk properties and concentration profiles is insufficient to ensure that the ensemble average converges, thus more repetitions should be conducted to provide robust results. While mean currents are statistically steady and weakly variable within the FOV, mixing is strongly transient and variable due to the turbulent nature of the background flow. In terms of the theoretical profiles, there are inherent difficulties in existing models to accurately predict the vertical concentration distribution of suspended particles. Indeed, studies have questioned the assumption of constant $\beta$ value over the entire water depth, based on the fact that both sediment and momentum diffusivity vary over the flow depth (Lin et al., 2012; Hughes, 1993; Graf and Cellino, 2002). Despite these findings, no universally-accepted values of this parameter nor its proper parametrization have been stablished, as is extensively discussed in Gualtieri et al. (2017). Additionally, Rouse analysis was theoretically developed for suspended transport in equilibrium conditions, considering the channel bed as sediment source. These assumptions differ from the current experiments where a point, instantaneous and surface source is used, leading to a non-equilibrium condition. These discrepancies highlight the need of further development of theoretical and modelling frameworks to address the suspension dynamics of coal (or other granular material) in non-equilibrium conditions, in order to predict contaminant fate from point sources and its implications on surrounding environment.

\section{Conclusions}

A simple and low-cost experimental procedure aimed to investigate if rhodamine can predict coal transport in water on a model scale is proposed. From the experiments, it was observed that the physical mechanisms governing the mixing and transport of these substances are fairly different. Transport processes for both fractions of coal (FF and CF) are divided into near- and far-field regimes controlled by the source and the background flow, respectively. Near the source, an intense mixing results from self-induced turbulence of the discharge and its interactions with the flow. Beyond this region, the effects of the discharge decay and the plume grows at a slower rate than in the near-field, driven by advection and turbulent diffusion of the suspended grains and superficial drift of the finest grains. The complex mixing pattern after the discharge is characterized by a strong sedimentation of large grains 
(specially for $\mathrm{CF}$ and to a lesser degree for $\mathrm{FF}$ ), followed by clusters of smaller grains retained at the surface which randomly disintegrate and fall as bursts. In the bottom, sediments are deposited showing negligible resuspension; few bubbles initially entrained by sediments to the bottom are randomly released. Rhodamine, conversely, shows a much simpler mixing pattern governed by advection and, to a lesser degree, by turbulent diffusion.

The presented results show that, if properly prepared and injected, the mixing of rhodamine resembles the finest fraction of coal that is transported as a suspended material, but fails in characterizing the larger coal grains that experience sedimentation. Further research is needed to understand resuspension of coal previously deposited in the bottom, particularly for cases where old deposits located in layers below the sea bottom may be suspended during intense coastal storms. From a forensic standpoint, additional tools (e.g. granulometry, petrography, electronic microscopy) could be used to compare samples collected on a polluted beach with coal deposits on nearby candidate sites (berth sites, stockpiles, conveyor belts). This, in combination with lab tests of in-situ raw samples (e.g. mixture of coal and sand) and hydrodynamic modelling, could aid in establishing the source of coal on a particular site.

The procedure was applied with relatively accessible equipment (an ADV, a level gauge and GoPro cameras) in combination with imaging techniques which could be easily implemented in small scale laboratories. Though it provides a good alternative because of its low cost and simplicity of use, more advanced techniques for measuring hydrodynamics (e.g. PIV) and mixing processes (e.g. 3DLIF) could aid in a better characterization of the mixing processes. The procedure could also be used to compare the mixing and/or transport of substances by other types of granular material (e.g. bulk material such as cereals) or liquid discharges (e.g. turbulent jets, sewage water outfalls) under forcing agents such as waves (Lin et al., 2012) tidal-, density- or wind-generated currents. Its implementation would require further research to reduce the inevitable scale effects on sediment/grain transport phenomena (in suspension and as bed load) yielding from the application of Froude similarity (Hughes, 1993).
Acknowledgments: The authors would like to acknowledge Ecotecnos for providing the coal samples.

Funding: This research was funded by Ecotecnos (https:// ecotecnos.cl/).

Conflicts of interest: The authors declare no conflict of interest. The funders had no role in the design of the study; in the collection, analyses, or interpretation of data; in the writing of the manuscript, or in the decision to publish the results.

Authorcontributions: Conceptualization and methodology: P.W., F.M. and M.R.; software development: A.G., R.A. and P.W.; physical modelling: F.M.; formal analysis: P.W., F.M., A.G., M.R., R.A. and J.S.; data curation: A.G., F.M. and J.S.; original draft preparation, review and editing: P.W. R.A.; supervision: P.W.; project administration: M.R.; funding acquisition: M.R., F.M. and P.W.

\section{Appendix A}

Table A1: a) Granulometry of the fine (Coal FF), b) coarse (Coal CF) samples (ASTM, 2005) and c) view of a coal sample a)

\begin{tabular}{|c|c|c|}
\hline \multicolumn{3}{|c|}{ Coal FF } \\
\hline Sieve & $\begin{array}{c}\text { Size, } \\
\text { mm }\end{array}$ & $\begin{array}{c}\text { Fraction } \\
\text { retained, \% }\end{array}$ \\
\hline 120 & 0.125 & 60 \\
\hline 230 & 0.063 & 35 \\
\hline Base & 0.031 & 5 \\
\hline
\end{tabular}

b)

\begin{tabular}{|c|c|c|}
\hline \multicolumn{3}{|c|}{ Coal CF } \\
\hline Sieve & $\begin{array}{c}\text { Size, } \\
\text { mm }\end{array}$ & $\begin{array}{c}\text { Fraction } \\
\text { retained, \% }\end{array}$ \\
\hline 5 & 4 & 3 \\
\hline 10 & 2 & 7 \\
\hline 18 & 1 & 10 \\
\hline 35 & 0.5 & 35 \\
\hline 60 & 0.25 & 45 \\
\hline
\end{tabular}

c)

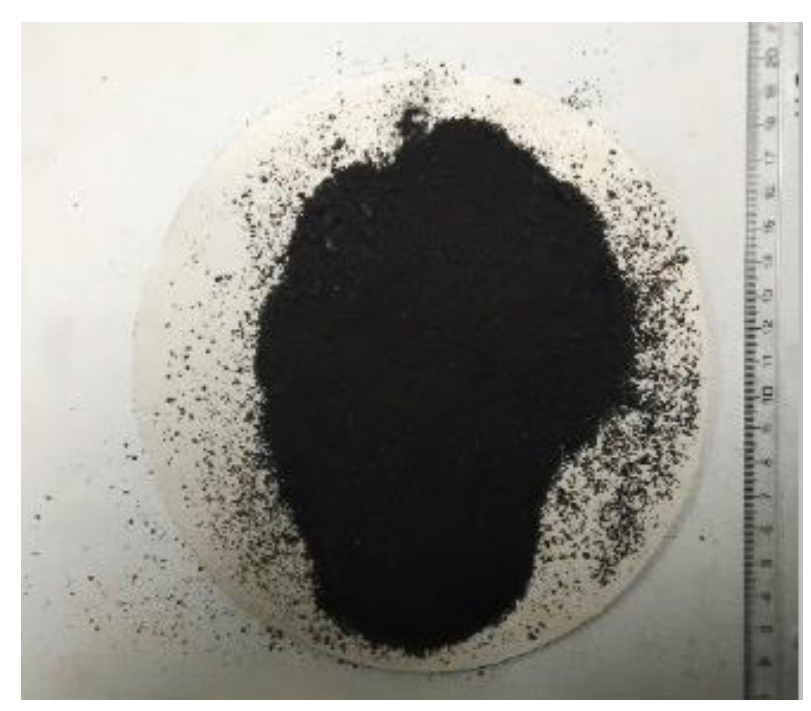


Winckler, P., Molteni, F., Reyes, M., Gubler, A., Sandoval, J. and Aleixo, R. (2021). Is Rhodamine a good tracer to predict coal transport in water?. Obras y Proyectos 30, 16-29

Table A2: Flow characteristics of the experiment and suspension parameters used to compute Rouse profile

\begin{tabular}{|c|c|c|}
\hline & \multicolumn{2}{|c|}{ Flow parameters } \\
\hline $\mathrm{U}, \mathrm{m} / \mathrm{s}$ & \multicolumn{2}{|c|}{0.05} \\
\hline $\mathrm{u}^{*}, \mathrm{~m} / \mathrm{s}$ & \multicolumn{2}{|c|}{0.0026} \\
\hline $\mathrm{Fr}$ & \multicolumn{2}{|c|}{0.03} \\
\hline $\mathrm{Re}$ & \multicolumn{2}{|c|}{$2.7 \times 10^{4}$} \\
\hline & \multicolumn{2}{|c|}{ Solute suspension parameters } \\
\hline & Fine coal & Coarse Coal \\
\hline $\mathrm{d}_{50}, \mathrm{~mm}$ & 0.14 & 0.54 \\
\hline $\mathrm{w}_{\mathrm{s}}, \mathrm{m} / \mathrm{s}$ & 0.0011 & 0.0105 \\
\hline $\mathrm{w}_{\mathrm{s}} / \mathrm{u}^{*}$ & 0.44 & 4.05 \\
\hline$\beta$ & 1.39 & 9.88 \\
\hline $\mathrm{Ro}$ & 0.77 & \multicolumn{2}{|c|}{} \\
\hline
\end{tabular}

\section{References}

Abessi, O. and Roberts, P.J.W. (2014). Multiport diffusers for dense discharges. Journal of Hydraulic Engineering 140(8), 04014032

Abessi, O. and Roberts, P.J.W. (2015). Dense jet discharges in shallow water. Journal of Hydraulic Engineering 142(1), 04015033

Ahrens, M.J. and Morrisey, D.J. (2005). Biological effects of unburnt coal in the marine environment. Oceanography and Marine Biology: An Annual Review, Gibson, R.N., Atkinson R.J.A., and Gordon, J.D.M. (eds.), Taylor and Francis, 43, 69-122 ASTM (2005). Standard test method for sieve analysis of fine and coarse aggregates. ASTM C136-05, ASTM International, West Conshohocken, PA, USA

Bennett, J.R. (1987). The physics of sediment transport, resuspension, and deposition. Hydrobiologia 149(1), 5-12

Berry, K.L., Hoogenboom, M.O., Flores, F. and Negri, A.P. (2016). Simulated coal spill causes mortality and growth inhibition in tropical marine organisms. Scientific Reports 6(1), 1-8

Choi, K.W., Lai, C.C. and Lee, J.H. (2015). Mixing in the intermediate field of dense jets in cross currents. Journal of Hydraulic Engineering 142(1), 04015041

Clark, D.B., Lenain, L., Feddersen, F., Boss, E. and Guza, R.T. (2014). Aerial imaging of fluorescent dye in the near shore. Journal of Atmospheric and Oceanic Technology 31(6):1410-1421
Coleman, N.L. (1970). Flume studies of the sediment transfer coefficient. Water Resources Research 6(3), 801-809

Daviero, G.J. and Roberts, P.J.W. (2006). Marine wastewater discharges from multiport diffusers. III: Stratified stationary water. Journal of Hydraulic Engineering 132(4), 404-410

Dey, S. (2014). Fluvial hydrodynamics. Springer, Berlin, Germany

Dietrich, W.E. (1982). Settling velocity of natural particles. Water Resources Research 18(6), 1615-1626

Fischer, H.B., List, J.E., Koh, C.R., Imberger, J. and Brooks, N.H. (2013). Mixing in inland and coastal waters. Elsevier

Franco-Herrera, A., Grijalba-Bendeck, L.M., Ibáñez, J.P. y Daza, J.N. (2011). Carbón, clima, playas y peces: el caso de la zona costera del departamento del Magdalena. Editorial Tadeo Lozano, Bogotá, Colombia

Goring, D.G. and Nikora, V.I. (2002). Despiking acoustic Doppler velocimeter data. Journal of Hydraulic Engineering 128(1), 117-126

Graf, W.H. and Cellino, M. (2002). Suspension flows in open channels; experimental study. Journal of Hydraulic Research 40(4), 435-447

Gualtieri, C., Angeloudis, A., Bombardelli, F., Jha, S. and Stoesser, T. (2017). On the values for the turbulent Schmidt number in environmental flows. Fluids 2(2), 17

Gungor, E. and Roberts, P.J.W. (2009). Experimental studies on vertical dense jets in a flowing current. Journal of Hydraulic Engineering 135(11), 935-948

Hughes, S.A. (1993). Physical models and laboratory techniques in coastal engineering. Advanced Series on Ocean Engineering, Volume 7. World Scientific Publishing, Singapore

IEA (2011). World energy outlook. International Energy Agency, Paris, France James, I.D. (2002). Modelling pollution dispersion, the ecosystem and water quality in coastal waters: a review. Environmental Modelling \& Software 17(4), 363-385

Jha, S.K. and Bombardelli, F.A. (2010). Toward two $\square$ phase flow modeling of nondilute sediment transport in open channels. Journal of Geophysical Research: Earth Surface 115(F3), F03015 
Johnson, R. and Bustin, R.M. (2006). Coal dust dispersal around a marine coal terminal (1977-1999), British Columbia: The fate of coal dust in the marine environment. International Journal of Coal Geology 68(1-2), 57-69

Julien, P.Y. (2010). Erosion and sedimentation. Cambridge University Press, UK

Klemas, V., Maurer, D., Leatham, W., Kinner, P. and Treasure, W. (1974). Dye and drogue studies of spoil disposal and oil dispersion. Journal (Water Pollution Control Federation) 46(8), 2026-2034

Lin, J.F., Hsiao, S.C., Hsu, T.W. and Chang, K.A. (2012). Buoyancy effect on turbulent round jet under regular waves. Journal of Waterway, Port, Coastal, and Ocean Engineering 139(3), 190-208

Moritz, H., Puckette, T., Marsh, J., Boudreau, R., Siipola, M. and Ott, M. (2011). Utilizing sediment tracer studies to evaluate transport pathways at the mouth of the Columbia River, USA. Coastal Sediments Specialty Conference, Miami, Florida, USA, 1565-1579

Muste, M., Yu, K., Fujita, I. and Ettema, R. (2005). Two $\square$ phase versus mixed $\square$ flow perspective on suspended sediment transport in turbulent channel flows. Water Resources Research 41(10), W10402

Roberts, P.J.W. and Tian, X. (2000). Three-dimensional imaging of stratified plume flows. $5^{\text {th }}$ International Conference on Stratified Flows, Vancouver, British Columbia, Canada

Roberts, P.J.W. and Tian, X. (2004). New experimental techniques for validation of marine discharge models. Environmental Modelling and Software 19(7-8), 691-699

Roberts, P.J.W., Tian, X. and Jung, Y. (2011). Physical model study of an alternating diffuser for thermal discharge. Journal of Hydraulic Engineering 137(9), 1027-1036

Rossi, V., Ser $\square$ Giacomi, E., López, C. and Hernández $\square$ García, E. (2014). Hydrodynamic provinces and oceanic connectivity from a transport network help designing marine reserves. Geophysical Research Letters 41(8), 2883-2891

Rouse, H. (1937). Modern conceptions of the mechanics of fluid turbulence. Transactions of the ASCE 102(1), 463-505

Royal Haskoning (2016a). Swansea channel sand tracing. Final Report. Elaborated for NSW Department of Primary Industries (Lands). Australia
Royal Haskoning (2016b). Old bar beach sediment tracing. Final Report. Elaborated for Greater Taree City Council. Australia Rypina, I.I., Kirincich, A. and Peacock, T. (2021). Horizontal and vertical spreading of dye in the coastal ocean of the northern Mid-Atlantic bight. Continental Shelf Research 230, 104567

Schweinfurth, S.P. (2009). An introduction to coal quality. The National Coal Resource Assessment Overview, Pierce, B.S. and Dennen, K.O. eds., US Geological Survey Professional Paper 1625-F, Chapter C, Virginia, USA

Smith, S.J., Marsh, J. and Puckette, T. (2007). Analysis of fluorescent sediment tracer for evaluating nearshore placement of dredged material. XVIII World Dredging Congress, Randell, R.E. (ed.), Florida, USA, 1345-1358

Takewaka, S., Misaki, S. and Nakamura, T. (2003). Dye diffusion experiment in a longshore current field. Coastal Engineering Journal 45(3), 471-487

Tang, L., Sheng, J., Hatcher, B.G. and Sale, P.F. (2006). Numerical study of circulation, dispersion, and hydrodynamic connectivity of surface waters on the Belize shelf. Journal of Geophysical Research: Oceans 111(C1), C01003

Tian, X., Roberts, P.J.W. and Daviero, G.J. (2004a). Marine wastewater discharges from multiport diffusers. I: Unstratified stationary water. Journal of Hydraulic Engineering 130(12), 1137-1146

Tian, X., Roberts, P.J.W. and Daviero, G.J. (2004b). Marine wastewater discharges from multiport diffusers. II: Unstratified flowing water. Journal of Hydraulic Engineering 130(12), 1147-1155

Tian, X., Roberts, P.J.W. and Daviero, G.J. (2006). Marine wastewater discharges from multiport diffusers. IV: Stratified flowing water. Journal of Hydraulic Engineering 132(4), 411-419

Tropea, C. and Yarin, A.L. (2007). Springer handbook of experimental fluid mechanics. Springer Science and Business Media.

Vanoni, V.A. (1975). Sediment discharge formulas. Sedimentation Engineering, ASCE, Manual and Reports on Engineering Practice 54, 190-229

Vroom, J., van Maren, B., Marsh, J. and van der Lelij, A.C. (2017). Effectiveness of the mud motor near Koehool. Results and interpretion of a tracer study. Deltares, Delft, the Netherlands WCA (2020). Coal and electricity. World Coal Association. https://www.worldcoal.org/coal/uses-coal/coal-electricity $(5 / 14 / 2020)$ 